\title{
Pengaruh Model Pembelajaran TPS Berbasis Lingkungan Terhadap Sikap Peduli Lingkungan Dan Kompetensi IPA
}

\author{
Ni Wayan Wiwik Saptiani ${ }^{*}$, I Gede Astawan² \\ ${ }^{12}$ Prodi Pendidikan Guru Sekolah Dasar, Universitas Pendidikan Ganesha, Indonesia
}

\section{A R T I CLE I N F O \\ Article history: \\ Received 18 Desember 2019 \\ Received in revised form 30 Desember 2019 \\ Accepted 15 Januari 2020 \\ Available online 20 \\ Februari 2020}

\section{Kata Kunci:}

TPS, sikap peduli

lingkungan, IPA,

\section{Keywords:}

environmental care attitude science knowledge

competence

\begin{abstract}
A B S T R A K
Penelitian ini bertujuan untuk mengetahui (1) perbedaan secara simultan sikap peduli lingkungan dan kompetensi IPA antara kelompok model pembelajaran kooperatif tipe Think Pair Share (TPS) berbasis lingkungan dan kelompok model pembelajaran konvensional, (2) perbedaan sikap peduli lingkungan antara kelompok model pembelajaran TPS berbasis lingkungan dan kelompok model pembelajaran konvensional, dan (3) perbedaan kompetensi IPA antara kelompok model pembelajaran TPS berbasis lingkungan dan kelompok model pembelajaran konvensional. Instrumen yang digunakan yaitu kuesioner dan tes pilihan ganda. Data yang diperoleh dianalisis dengan menggunakan statistik deskriptif dan inferensial yaitu uji manova. Hasil penelitian menujukkan (1) terdapat perbedaan secara simultan sikap peduli lingkungan dan kompetensi IPA antara kelompok model pembelajaran kooperatif tipe Think Pair Share (TPS) berbasis lingkungan dan kelompok model pembelajaran konvensional yang dibuktikan dengan nilai sig (2-tailed) sebesar $0,000<0,05$. (2) terdapat perbedaan sikap peduli lingkungan antara kelompok model pembelajaran TPS berbasis lingkungan dan kelompok model pembelajaran konvensional yang dibuktikan dengan nilai sig sebesar 0,000 $<0,05$. (3) terdapat perbedaan kompetensi IPA antara kelompok model
\end{abstract} pembelajaran TPS berbasis lingkungan dan kelompok model pembelajaran konvensional yang dibuktikan dengan nilai sig sebesar $0,013<0,05$.

\section{A B S T R A C T}

This study aimed to find out (1) simultaneous differences in environmental care and science competencies between groups of cooperative learning models based on Think Pair Share (TPS) and conventional learning model groups, (2) differences in environmental care attitudes between groups of environment-based TPS learning models and groups of conventional learning models, and (3) differences in natural science competencies between groups of environment-based TPS learning models and conventional learning model groups. The instruments used were questionnaires and multiple-choice tests. The data obtained were analyzed using descriptive and inferential statistics, namely the manova test. The results of the study show (1) there were differences in the simultaneous environmental care attitude and science competency between the group based cooperative learning model Think Pair Share (TPS) environment and the conventional learning model group as evidenced by the sig $(2$-tailed) value of $0,000<0.05$. (2) there were differences in environmental care attitudes between groups of environment-based TPS learning models and groups of conventional learning models as evidenced by the sig value of $0,000<0,05$. (3) there were differences in science competencies between groups of TPS-based learning model environment and groups of conventional learning models as evidenced by the sig value of $0.013<0.05$.

Copyright (C) Universitas Pendidikan Ganesha. All rights reserved.

\section{Pendahuluan}

Kemajuan suatu bangsa dapat dinilai dari kualitas Sumber Daya Manusia (SDM). SDM yang berkualitas merupakan kunci untuk menjadi bangsa yang maju. SDM yang berkualitas diharapkan mampu mengadakan perubahan bagi Indonesia ke arah yang lebih baik. Untuk itu, pendidikan memegang peran penting dalam usaha menyiapkan SDM yang berkualitas. Seiring dengan perkembangan zaman, pendidikan di jenjang sekolah dasar mengalami perubahan, terutama pada penyempurnaan kurikulum. Saat ini, hampir seluruh sekolah dasar telah menerapkan Kurikulum 2013 (Suherman, 2014).

Mata pelajaran IPA merupakan salah satu mata pelajaran pokok yang ada pada Kurikulum 2013 di SD. Bundu (2006:9) menyatakan "IPA secara harfiah dapat disebut sebagai ilmu pengetahuan tentang

\footnotetext{
${ }^{1}$ Corresponding author.

E-mail addresses: wayan.wiwik.saptiani@undiksha.ac.id ${ }^{1}$, (Wiwik) igedeastawan@undiksha.ac.id² (Astawan)
} 
alam atau yang mempelajari peristiwa-peristiwa yang terjadi di alam." Dengan pemahaman terhadap materi IPA, siswa diharapkan lebih aktif dalam proses pembelajaran, memiliki daya ingat yang baik dan mampu berpikir secara kritis dalam menyikapi peristiwa-peristiwa yang terjadi di lingkungan sekitarnya. Pembelajaran IPA di SD juga berkaitan dengan nilai-nilai karakter, karena pendidikan karakter sangat penting bagi perkembangan siswa. Kemendiknas (2011) menyatakan, dalam rangka lebih memperkuat pelaksanaan pendidikan karakter yang penting untuk dimiliki oleh peserta didik pada satuan pendidikan telah teridentifikasi 18 nilai karakter yang bersumber dari agama, Pancasila, budaya, dan tujuan pendidikan nasional, yaitu: (1) religius, (2) jujur, (3) toleransi, (4) disiplin, (5) kerja keras, (6) kreatif, (7) mandiri, (8) demokratis, (9) rasa ingin tahu, (10) semangat kebangsaan, (11) cinta tanah air, (12) menghargai prestasi, (13) bersahabat/komunikatif, (14) cinta damai, (36) gemar membaca, (16) peduli lingkungan, (17) peduli sosial, (18) tanggung jawab.

Salah satu dari 18 karakter yang penting untuk dimiliki peserta didik dalam pelaksanaan pendidikan karakter adalah sikap peduli lingkungan. Menurut Yaumi (dalam Febrianti, 2017:18) "sikap peduli lingkungan merupakan sikap dan tindakan yang selalu berupaya mencegah kerusakan pada lingkungan alam di sekitarnya dan mengembangkan upaya-upaya untuk meperbaiki kerusakan alam yang sudah terjadi." Selain ditinjau dari 18 nilai karakter, sikap peduli lingkungan juga mempengaruhi nilai sikap peduli pada Kompetenti Inti 2 (KI-2) dalam Kurikulum 2013. Penanaman sikap peduli lingkungan perlu dilakukan sejak dini, misalnya melalui pendidikan formal di sekolah dasar.

Berdasarkan hasil dokumentasi nilai UAS di sekolah, dapat disajikan nilai sikap peduli dan kompetensi IPA pada Tabel 01 dan Tabel 02.

Tabel 01 Nilai Sikap Peduli dalam Nilai Sosial (KI-2) Kelas IV SD di Gugus VIII Kecamatan Seririt

\begin{tabular}{|c|c|c|c|c|}
\hline No & Sekolah Populasi & $\begin{array}{l}\text { Rata-Rata Kategori } \\
\text { Peduli }\end{array}$ & Sikap & $\begin{array}{l}\text { Jumlah } \\
\text { Siswa }\end{array}$ \\
\hline 1 & SD N 1 Banjar Asem & Perlu Bimbingan (PB) & & 22 \\
\hline 2 & SD N 2 Banjar Asem & Perlu Bimbingan (PB) & & 33 \\
\hline 3 & SD N 3 Banjar Asem & Perlu Bimbingan (PB) & & 7 \\
\hline 4 & SD N 1 Kalisada & Perlu Bimbingan (PB) & & 17 \\
\hline 5 & SD N 2 Kalisada & Perlu Bimbingan (PB) & & 19 \\
\hline 6 & SD N 1 Pangkungparuk & Perlu Bimbingan (PB) & & 21 \\
\hline 7 & SD N 3 Pangkungparuk & Perlu Bimbingan (PB) & & 40 \\
\hline 8 & SD N 4 Pangkungparuk & Perlu Bimbingan (PB) & & 26 \\
\hline
\end{tabular}

Tabel 02 Nilai Kompetensi IPA Kelas IV SD di Gugus VIII Kecamatan Seririt

\begin{tabular}{llllll}
\hline No & Sekolah Populasi & KKM & $\begin{array}{l}\text { Persentase } \\
\text { Siswa } \\
\text { bawah KKM }\end{array}$ & $\begin{array}{l}\text { Rata- } \\
\text { rata } \\
\text { Nilai }\end{array}$ & $\begin{array}{l}\text { Jumlah } \\
\text { Siswa }\end{array}$ \\
\hline 1 & SD N 1 Banjar Asem & 63 & $91 \%$ & 50,91 & 22 \\
2 & SD N 2 Banjar Asem & 61 & $88 \%$ & 48,78 & 33 \\
3 & SD N 3 Banjar Asem & 63 & $86 \%$ & 43,29 & 7 \\
4 & SD N 1 Kalisada & 68 & $82 \%$ & 48,17 & 17 \\
5 & SD N 2 Kalisada & 63 & $89 \%$ & 52,47 & 19 \\
6 & SD N 1 Pangkungparuk & 64 & $81 \%$ & 46,86 & 21 \\
7 & SD N 3 Pangkungparuk & 63 & $90 \%$ & 48,55 & 40 \\
8 & SD N 4 Pangkungparuk & 63 & $88 \%$ & 54,46 & 26 \\
\hline
\end{tabular}

Tabel 01 menunjukkan nilai sikap peduli siswa di Gugus VIII masih banyak yang perlu bimbingan dan Tabel 02 menunjukkan nilai rata-rata kompetensi IPA siswa kelas IV SD Gugus VIII Kecamatan Seririt masih banyak yang di bawah KKM. Kondisi demikian apabila dibiarkan akan berdampak kurang optimal terhadap kualitas pembelajaran IPA di SD Gugus VIII Kecamatan Seririt. Dengan demikian, sangat penting bagi guru-guru SD di Gugus VIII Kecamatan Seririt untuk menerapkan berbagai model pembelajaran yang bervariasi sehingga melibatkan siswa secara aktif dalam proses pembelajaran. Proses pembelajaran dapat dilakukan dengan model pembelajaran yang sesuai dengan kondisi yang dialami oleh siswa dan kurikulum yang diterapkan pada saat ini. Salah satu model pembelajaran yang relevan sebagai solusi 
alternatif terhadap permasalahan di atas adalah model pembelajaran kooperatif tipe Think Pair Share (TPS).

Model pembelajaran kooperatif tipe TPS adalah salah satu model pembelajaran yang memberikan siswa kesempatan untuk berpikir cepat dan bekerjasama dengan siswa lain dalam memecahkan masalah sehingga mampu memengaruhi pola interaksi siswa saat proses pembelajaran berlangsung (Kurniasih dan Berlin, 2016). Model pembelajaran kooperatif tipe TPS memiliki beberapa keunggulan yaitu, memberikan siswa waktu lebih banyak untuk berpikir, menjawab, saling membantu satu sama lain, memberikan kesempatan kepada siswa untuk memperdalam jawaban yang telah dipikirkan dengan pasangannya, siswa lebih aktif dalam pembelajaran karena bekerjasama menyelesaikan tugasnya dalam kelompok dimana tiap kelompok hanya terdiri dari 2 orang, siswa dapat belajar dari siswa lain serta saling menyampaikan idenya untuk didiskusikan sebelum disampaikan di depan kelas dan dapat melatih rasa percaya diri siswa karena semua siswa diberi kesempatan untuk berpartisipasi di dalam kelas (Suprijono, 2009).

Model pembelajaran akan lebih efektif, apabila selama proses pembelajaran siswa dilibatkan secara langsung. Hal ini dikarenakan, belajar pada hakekatnya adalah suatu interaksi antara individu dan lingkungan. Lingkungan menyediakan ransangan (stimulus) terhadap individu dan sebaliknya individu memberikan respons terhadap lingkungan. Dalam proses interaksi itu dapat terjadi perubahan pada diri individu, berupa perubahan tingkah laku. Oleh sebab itu, guru harus dapat melibatkan lingkungan terdekat siswa dalam proses pembelajaran, karena lingkungan adalah salah satu sumber belajar yang amat penting (Deyuter, 2013). De Porter, et al. (dalam Astawan dan Rati, 2016:2) mengungkapkan bahwa, pengaturan lingkungan belajar sangat berperan dalam menciptakan suasana belajar yang nyaman, salah satunya pengaturan meja belajar.

\section{Metode}

Rancangan penelitian yang digunakan adalah posttest-only control-group design. Populasi dalam penelitian ini adalah semua siswa kelas IV SD Gugus VIII Kecamatan Seririt yang menggunakan Kurikulum 2013 yakni sebanyak 185 orang. Sebaran populasi dapat dilihat pada Tabel 03.

Tabel 03 Populasi Kelas IV di SD Gugus VIII Kecamatan Seririt

\begin{tabular}{clcc}
\hline No & \multicolumn{1}{c}{ Nama Sekolah } & Kelas & Jumlah Siswa \\
\hline 1 & SD N 1 Banjar Asem & IV & 22 \\
2 & SD N 2 Banjar Asem & IV & 33 \\
3 & SD N 3 Banjar Asem & IV & 7 \\
4 & SD N 1 Kalisada & IV & 17 \\
5 & SD N 2 Kalisada & IV & 19 \\
6 & SD N 1 Pangkungparuk & IV & 21 \\
7 & SD N 3 Pangkungparuk & IV & 40 \\
8 & SD N 4 Pangkungparuk & IV & 26 \\
\hline & Jumlah & & $\mathbf{1 8 5}$ \\
\hline
\end{tabular}

Dalam penelitian ini, sampel ditentukan dengan menggunakan group random sampling, dengan teknik undian (Agung, 2017). Berdasarkan sistem undian yang telah dilakukan, maka dapat disimpulkan bahwa SD N 2 Banjar Asem sebagai kelompok eksperimen dan SD N 3 Pangkungparuk sebagai kelompok kontrol. Data sikap peduli lingkungan siswa dengan kuesioner. Kuesioner menggunakan skala Likert. Data kompetensi IPA menggunakan tes pilihan ganda.

Data yang dikumpulkan adalah sikap peduli lingkungan dan kompetensi IPA. Kompetensi IPA berpedoman pada landasan Kurikulum 2013. Sedangkan instrumen sikap peduli lingkungan dengan indikator 1) menjaga lingkungan kelas dan sekolah, 2) memelihara tumbuh-tumbuhan dengan baik tanpa menginjak atau merusaknya, 3) mendukung program go green (penghijauan) di lingkungan sekolah, 4) tersedianya tempat untuk membuang sampah organik dan sampah anorganik dan 5) menyediakan kamar mandi, air bersih, dan tempat mencuci tangan (Fitri (dalam wati, 2017). Hasil penelitian ini dianalisis secara bertahap, yaitu: analisis deskriptif dan inferensial. Data dianalisis menggunakan uji manova dengan bantuan SPSS 17.00 for windows pada signifikansi 5\%. 


\section{Hasil Dan Pembahasan}

Hasil penelitian secara deskriptif memaparkan tentang hasil perhitungan mean, standar deviasi, range, skor maksimum, skor minimum. Hasil analisis data menunjukkan bahwa secara deskriptif kelompok yang belajar menggunakan model pembelajaran kooperatif tipe TPS berbasis lingkungan lebih tinggi dibandingkan kelompok siswa yang dibelajarkan dengan pembelajaran konvensional. Rangkuman hasil analisis deskriptif disajikan pada Tabel 04.

Tabel 04 Rangkuman Statistik Deskriptif Variabel Penelitian

\begin{tabular}{lcccc}
\hline \multirow{2}{*}{ Statistik } & \multicolumn{2}{c}{ A1 } & Y1 & A2 \\
\cline { 2 - 5 } $\mathrm{N}$ & Y1 & Y2 & 30 & 30 \\
Mean & 30 & 30 & 119,93 & 75,6 \\
Standar Deviasi & 132,27 & 84 & 6,57 & 9,51 \\
Range & 5,83 & 9,03 & 23 & 40 \\
Minimum & 25 & 40 & 134 & 56 \\
Maksimum & 144 & 60 & 111 & 96 \\
\hline
\end{tabular}

Tabel 04 menunjukkan bahwa, hasil perhitungan mean, standar deviasi, range, skor maksimum, dan skor minimum kelompok eksperimen lebih tinggi dibandingkan kelompok kontrol. Uji prasyarat yang dilakukan adalah uji normalitas sebaran data, uji homogenitas varians, dan uji korelasi antar variabel terikat, sebelum dilakukan uji hipotesis. Analisis menggunakan bantuan SPSS-17.00 for windows (Candiasa, 2010).

Berdasarkan hasil analisis data normalitas didapatkan hasil (1) nilai signifikasnsi sikap peduli lingkungan kelas eksperimen sebesar 0,178 >0,05, yang berarti data berdistribusi normal. (2) nilai signifikasnsi sikap peduli lingkungan kelas kontrol sebesar 0,77 $>0,05$, yang berarti data berdistribusi normal. (3) nilai signifikasnsi kompetensi IPA kelas eksperimen sebesar 0,86 > 0,05, yang berarti data berdistribusi normal. (4) nilai signifikansi kompetensi IPA kelas kontrol sebesar 0,144 >0,05, yang berarti data berdistribusi normal.

Berdasarkan hasil analisis data homogenitas varians didapatkan hasil bahwa nilai signifikansi di atas 5\% yang berarti data bersifat homogen. Selanjutnya hasil analisis korelasi data didapatkan hasil bahwa signifikansi (2-tailed) di atas 5\% yang berarti tidak terdapat korelasi dan data dapat dilanjutkan dengan Uji Manova.

Hasil uji hipotesis dalam penelitian ini membuktikan bahwa: pertama, secara simultan, terdapat perbedaan sikap peduli lingkungan dan kompetensi IPA antara siswa yang mengikuti model pembelajaran kooperatif tipe TPS berbasis lingkungan dan siswa yang mengikuti pembelajaran konvensional. Hasil analisis disajikan pada Tabel 05.

Tabel 05 Rangkuman Multivariate Test

\begin{tabular}{|c|c|c|c|c|c|c|}
\hline Effect & & Value & $\mathbf{F}$ & $\begin{array}{c}\text { Hypothesis } \\
\text { df }\end{array}$ & Error df & Sig. \\
\hline \multirow[t]{4}{*}{ Intercept } & Pillai's Trace & .998 & $12809.988^{a}$ & 2.000 & 57.000 & .000 \\
\hline & Wilks' Lambda & .002 & $12809.988^{a}$ & 2.000 & 57.000 & .000 \\
\hline & Hotelling's Trace & 449.473 & $12809.988^{a}$ & 2.000 & 57.000 & .000 \\
\hline & Roy's Largest Root & 449.473 & $12809.988^{a}$ & 2.000 & 57.000 & .000 \\
\hline \multirow[t]{4}{*}{ Kelas } & Pillai's Trace & .490 & $27.409^{a}$ & 2.000 & 57.000 & .000 \\
\hline & Wilks' Lambda & .510 & $27.409^{a}$ & 2.000 & 57.000 & .000 \\
\hline & Hotelling's Trace & .962 & $27.409^{a}$ & 2.000 & 57.000 & .000 \\
\hline & Roy's Largest Root & .962 & $27.409^{a}$ & 2.000 & 57.000 & .000 \\
\hline
\end{tabular}


Tabel 05 menunjukan bahwa, nilai F Pillai's Trace, Wilks' Lambda, Hotelling Trace, Roy's Largest Root adalah 27.409 seluruhnya memiliki signifikansi 0,000 dan lebih kecil dari 0,05 $(0,000<0,05)$, sehingga $\mathrm{H}_{0}$ ditolak dan $\mathrm{H}_{1}$ diterima. Berdasarkan hasil analisis uji hipotesis 1 dapat disimpulkan bahwa terdapat perbedaan secara simultan sikap peduli lingkungan dan kompetensi IPA antara siswa yang mengikuti model pembelarajan kooperatif tipe TPS berbasis lingkungan dengan siswa yang mengikuti model pembelajaran konvensional pada siswa kelas IV SD Gugus VIII Kecamatan Seririt.

Kedua, hasil analisis menunjukkan terdapat perbedaan sikap peduli lingkungan antara siswa yang mengikuti model pembelajaran kooperatif tipe TPS berbasis lingkungan dan siswa yang mengikuti pembelajaran konvensional. Adapun ringkasan analisis data hipotesis 2 dapat dilihat pada Tabel 06 dan Tabel 07.

Tabel 06 Tests of Between-Subjects Effects

\begin{tabular}{|c|c|c|c|c|c|c|}
\hline Source & Dependent Variable & $\begin{array}{l}\text { Type III Sum of } \\
\text { Squares }\end{array}$ & df & $\begin{array}{l}\text { Mean } \\
\text { Square }\end{array}$ & $\mathbf{F}$ & Sig. \\
\hline \multirow[t]{2}{*}{ Corrected Model } & Sikap_peduli_lingkungan & $2148.017^{a}$ & 1 & 2148.017 & 48.572 & .000 \\
\hline & $\begin{array}{l}\text { Kompetensi_pengetahuan_IP } \\
\text { A }\end{array}$ & $608.017^{b}$ & 1 & 608.017 & 6.608 & .013 \\
\hline \multirow[t]{2}{*}{ Intercept } & Sikap_peduli_lingkungan & 959882.017 & 1 & $\begin{array}{r}959882.01 \\
7\end{array}$ & $\begin{array}{r}21705.2 \\
17\end{array}$ & .000 \\
\hline & $\begin{array}{l}\text { Kompetensi_pengetahuan_IP } \\
\text { A }\end{array}$ & 372724.017 & 1 & $\begin{array}{r}372724.01 \\
7\end{array}$ & $\begin{array}{r}4050.61 \\
4\end{array}$ & .000 \\
\hline \multirow[t]{2}{*}{ Kelompok } & Sikap_peduli_lingkungan & 2148.017 & 1 & 2148.017 & 48.572 & .000 \\
\hline & $\begin{array}{l}\text { Kompetensi_pengetahuan_IP } \\
\text { A }\end{array}$ & 608.017 & 1 & 608.017 & 6.608 & .013 \\
\hline
\end{tabular}

Tabel 07 Pairwise Comparisons

\begin{tabular}{|c|c|c|c|c|c|c|c|}
\hline \multirow[b]{2}{*}{ Dependent Variable } & \multirow{2}{*}{$\begin{array}{l}(\mathrm{I}) \\
\text { kelompok } \\
(1,2)\end{array}$} & \multirow{2}{*}{$\begin{array}{l}(\mathrm{J}) \\
\text { kelompok } \\
(1,2)\end{array}$} & \multirow{2}{*}{$\begin{array}{c}\text { Mea } \\
\text { n } \\
\text { Diffe } \\
\text { renc } \\
\text { e (I- } \\
\text { J) }\end{array}$} & \multirow[b]{2}{*}{$\begin{array}{c}\text { Std. } \\
\text { Error }\end{array}$} & \multirow[b]{2}{*}{ Sig. ${ }^{a}$} & \multicolumn{2}{|c|}{$\begin{array}{l}\text { 95\% Confidence } \\
\text { Interval for } \\
\text { Difference }^{\mathbf{a}}\end{array}$} \\
\hline & & & & & & $\begin{array}{l}\text { Lower } \\
\text { Bound }\end{array}$ & $\begin{array}{l}\text { Upper } \\
\text { Bound }\end{array}$ \\
\hline \multirow[t]{2}{*}{ Sikap_peduli_lingkungan } & eksperimen & kontrol & $\begin{array}{r}11.96 \\
7^{*}\end{array}$ & 1.717 & .000 & 8.530 & 15.404 \\
\hline & kontrol & eksperimen & $\begin{array}{r}- \\
11.96 \\
7^{*}\end{array}$ & 1.717 & .000 & -15.404 & -8.530 \\
\hline \multirow[t]{2}{*}{ Kompetensi_pengetahuan_IPA } & eksperimen & kontrol & $\begin{array}{r}6.367 \\
*\end{array}$ & 2.477 & .013 & 1.409 & 11.324 \\
\hline & kontrol & eksperimen & $\begin{array}{r}- \\
6.367 \\
*\end{array}$ & 2.477 & .013 & -11.324 & -1.409 \\
\hline
\end{tabular}

Berdasarkan Tabel 06, nilai signifikansi sikap peduli lingkungan pada kolom kelompok adalah 0,000 lebih kecil dari 0,05 $(0,000<0,05)$, sehingga $\mathrm{H}_{0}$ ditolak dan $\mathrm{H}_{1}$ diterima. Dapat disimpulkan bahwa, terdapat perbedaan sikap peduli lingkungan antara siswa yang mengikuti model pembelarajan kooperatif tipe TPS berbasis lingkungan dan siswa yang mengikuti model pembelajaran konvensional pada siswa kelas IV SD Gugus VIII Kecamatan Seririt. Kemudian, ditindaklanjuti Tabel 07 pada kolom sikap peduli lingkungan, nilai Mean Difference (I-J) sebesar 11.967 (bernilai positif) dengan signifikansi sebesar 0,000 $<0,05$, yang artinya kelompok eksperimen lebih baik dari kelompok kontrol.

Ketiga, hasil analisis menunjukkan bahwa terdapat perbedaan kompetensi IPA antara siswa yang mengikuti model pembelajaran kooperatif tipe TPS berbasis lingkungan dan siswa yang mengikuti 
pembelajaran konvensional. Berdasarkan Tabel 06, nilai signifikansi kompetensi IPA pada kolom kelompok adalah 0,013 lebih kecil dari 0,05 $(0,013<0,05)$, sehingga $\mathrm{H}_{0}$ ditolak dan $\mathrm{H}_{1}$ diterima. Dapat disimpulkan bahwa, terdapat perbedaan kompetensi IPA antara siswa yang mengikuti model pembelarajan kooperatif tipe TPS berbasis lingkungan dan siswa yang mengikuti model pembelajaran konvensional pada siswa kelas IV SD Gugus VIII Kecamatan Seririt. Kemudian, ditindaklanjuti Tabel 07 pada kolom kompetensi IPA, nilai Mean Difference (I-J) sebesar 6.367 (bernilai positif) dengan signifikansi sebesar 0,013<0,05, yang artinya kelompok eksperimen lebih baik dari kelompok kontrol.

Temuan pertama menunjukkan bahwa terdapat perbedaan yang simultan sikap peduli lingkungan dan kompetensi IPA antara siswa yang mengikuti model pembelajaran kooperatif tipe TPS berbasis lingkungan dan siswa yang mengikuti pembelajaran konvensional pada siswa kelas IV SD di Gugus VIII Kecamatan Seririt. Pencapaian sikap peduli lingkungan dan kompetensi IPA kelompok eksperimen lebih tinggi dibandingkan dengan kelompok kontrol. Dengan kata lain, bahwa model pembelajaran kooperatif tipe TPS berbasis lingkungan lebih unggul dari model pembelajaran konvensional.

Dalam pembelajaran guru merupakan salah satu faktor penting yang dapat mempengaruhi sikap peduli lingkungan dan kompetensi pengetahuan IPA siswa. Guru dapat memilih model yang diterapkan dalam proses pembelajaran di kelas maupun di luar kelas. Pemilihan model yang tepat akan memberikan manfaat bagi proses pembelajaran. Dalam proses pembelajaran, pasti ada siswa yang mengalami kesulitan sehingga menimbulkan pertanyaan dari siswa tersebut. Oleh karena itu, guru harus bisa memilih model yang tepat dan inovatif untuk meningkatkan sikap peduli lingkungan dan kompetensi pengetahuan IPA siswa (Suprijono, 2009).

Pembelajaran dengan model Think Pair Share (TPS) berbasis lingkungan memberikan kesempatan bagi siswa untuk berlatih secara mandiri melalui umpan balik dari teman atau guru. Pembelajaran ini membuat siswa antusias bekerja sama dengan kelompoknya untuk saling berbagi informasi secara bersamaan. Selain itu, siswa terlatih untuk berani berbicara mengemukakan pendapat di depan kelas. Penelitian yang telah dilakukan peneliti menunjukkan bahwa model pembelajaran kooperatif tipe TPS berbasis lingkungan membawa dampak yang positif terhadap sikap peduli lingkungan dan kompetensi pengetahuan IPA siswa. Pembelajaran dengan menggunakan model TPS berbasis lingkungan diterapkan di dalam maupun luar kelas. Model TPS memiliki sintaks yang terdiri dari 3 fase (fase think, fase pairing, fase sharing) untuk meningkatkan antusias belajar siswa (Kurniasih dan Berlin, 2016).

Fase think (berpikir), siswa diberikan sebuah permasalahan terkait materi gaya atau gerak yang dihubungkan dengan lingkungan sekitar. Kemudian, siswa berpikir secara individual untuk meningkatkan rasa ingin tahu. Dengan berpikir, siswa dapat melatih ingatan terkait permasalahan yang ada di lingkungan sekitar. Sehingga, sikap peduli lingkungan dan kompetensi pengetahuan IPA siswa dapat ditingkatkan. Sejalan dengan pendapat Suprijono (2009), fase think (berpikir) menjadikan pengetahuan siswa semakin berkembang. Selanjutnya, berdasarkan temuan Deyuter (2013), model kooperatif tipe TPS berbasis lingkungan dapat meningkatkan hasil belajar IPA siswa, karena lingkungan adalah salah satu sumber belajar yang amat penting dan memiliki nilai-nilai yang sangat berharga dalam rangka proses pembelajaran siswa.

Fase pairing (berpasangan), setelah siswa berpikir secara individual, guru meminta siswa untuk berdiskusi bersama teman sebangkunya. Dengan berpasangan, siswa dapat saling melengkapi jawaban temannya, sehingga pengetahuan siswa semakin luas dan sifatnya tidak terbatas. Sejalan dengan pendapat Suprijono (2009), Fase pairing merupakan kegiatan bersama kelompok kecil yang terdiri dari 2 orang siswa. Tujuan dari pairing ini adalah untuk meningkatkan kerjasama siswa dalam kelompok dan saling berbagi ilmu pengetahuan dengan pasangannya. Selanjutnya, sesuai dengan temuan Suryaningsih (2017), model kooperatif tipe TPS dapat meningkatkan kompetensi pengetahuan IPA, karena model TPS memiliki banyak keunggulan, salah satunya adalah dapat meningkatkan kerja sama dengan teman sebangku dan menambah wawasan pengetahuan.

Fase sharing (berbagi), siswa bersama pasangannya meyampaikan hasil diskusi di depan kelas. Kegiatan sharing mampu menjadikan siswa lebih aktif dan percaya diri dalam proses pembelajaran. Setelah siswa selesai menyampaikan jawaban di depan kelas, selanjutnya diadakan sesi diskusi dan tanya jawab, agar kelompok yang lain mendapatkan wawasan dari jawaban siswa yang tampil di depan kelas. Suprijono (2009), kegiatan sharing dapat menjadikan siswa lebih percaya diri dan melatih kemampuan siswa dalam berkomunikasi. Dengan demikian, kemampuan belajar siswa menjadi lebih baik. Jadi, sikap peduli lingkungan dan kompetensi pengetahuan IPA siswa setelah dibelajarkan dengan model TPS berbasis lingkungan lebih baik dari model pembelajaran konvensional.

Model pembelajaran konvensional menjadikan siswa kurang aktif karena proses pembelajaran didominasi oleh guru (teacher-centered). Proses pembelajaran pada kelompok kontrol hanya 
menggunakan metode ceramah, diskusi, dan tanya jawab. Siswa yang ada di kelompok kontrol tidak dapat mengeksplor kemampuannya secara maksimal. Hal tersebut sesuai dengan pendapat Santyasa (2005) yang menyatakan bahwa pembelajaran konvensional bersifat "teacher directed." Berdasarkan pendapat tersebut dapat diketahui pembelajaran konvensional adalah rangkaian kegiatan pembelajaran yang didominasi oleh guru, sedangkan siswa hanya mengandalkan guru sebagai sumber informasi. Dengan kata lain, pembelajaran konvensional lebih berpusat pada guru. Penyampaian materi dalam pembelajaran lebih banyak dilakukan melalui ceramah, tanya jawab, dan penugasan yang berlangsung terus menerus.

Model pembelajaran kooperatif tipe TPS memiliki banyak keunggulan yang menjadikan siswa lebih aktif. Hal ini, sesuai dengan pendapat Zaini (dalam Suwatra, dkk., 2015) menyatakan pembelajaran aktif adalah suatu pembelajaran yang mengajak peserta didik untuk belajar secara aktif. Dengan belajar aktif, kegiatan pembelajaran akan lebih berpusat kepada siswa yang dapat mempengaruhi keaktifan belajar siswa. Siswa yang cenderung diam akan terpancing untuk bergerak. Pembelajaran ini tidak hanya melibatkan mental siswa, akan tetapi juga melibatkan fisik siswa.

Dalam hal ini, guru sangat berperan penting untuk membimbing siswa melakukan diskusi, sehingga terciptanya suasana belajar yang kondusif, aktif, kreatif dan menyenangkan. Guru juga dapat memotivasi siswa untuk belajar dan saling membantu satu sama lain, maka siswa dapat bekerja dengan lebih efektif sehingga mendapatkan hasil belajar yang lebih baik.

Berdasarkan penelitian yang telah dilakukan dan diperkuat oleh pendapat di atas, memperkuat bahwa model pembelajaran kooperatif tipe TPS berbasis lingkungan pada proses pembelajaran berpengaruh signifikan terhadap sikap peduli lingkungan dan kompetensi pengetahuan IPA siswa.

Temuan kedua menunjukkan bahwa terdapat perbedaan sikap peduli lingkungan antara siswa yang mengikuti model pembelajaran kooperatif tipe TPS berbasis lingkungan dengan siswa yang mengikuti pembelajaran konvensional pada siswa kelas IV SD di Gugus VIII Kecamatan Seririt. Sikap peduli lingkungan siswa setelah dibelajarkan dengan model pembelajaran kooperatif tipe TPS berbasis lingkungan lebih baik daripada siswa yang dibelajarkan dengan pembelajaraan konvensional. Sikap peduli lingkungan sangat penting untuk ditingkatkan oleh siswa, karena sikap peduli lingkungan mecerminkan sesuatu yang positif dalam diri siswa.

Menurut Deyuter (2013) menyatakan, model pembelajaran TPS berbasis lingkungan merupakan salah satu model pembelajaran kooperatif yang melibatkan siswa untuk melakukan diskusi kelompok dan sharing pengetahuan dengan berbantuan lingkungan sebagai sumber belajar. Hal tersebut dapat mengoptimalkan potensi siswa untuk meningkatkan sikap peduli lingkungan. Selain itu, menurut Yaumi (dalam Febrianti, 2017:18), "sikap peduli lingkungan merupakan sikap dan tindakan yang selalu berupaya mencegah kerusakan pada lingkungan alam di sekitarnya, dan mengembangkan upaya-upaya untuk memperbaiki kerusakan alam yang sudah terjadi". Temuan ini sejalan dengan penelitian Deyuter (2013) yang mengungkapkan bahwa model pembelajaran kooperatif tipe TPS berbasis lingkungan berpengaruh signifikan terhadap hasil belajar siswa. Siswa yang belajar dengan model pembelajaran kooperatif tipe TPS berbasis lingkungan jauh lebih baik dari pembelajaran konvensional.

Berdasarkan penelitian yang dilakukan dan diperkuat oleh beberapa pendapat di atas, memperkuat bahwa model pembelajaraan kooperatif tipe TPS berbasis lingkungan berpengaruh terhadap sikap peduli lingkungan siswa.

Temuan ketiga menunjukkan bahwa terdapat perbedaan kompetensi IPA antara siswa yang mengikuti model pembelajaran kooperatif tipe TPS berbasis lingkungan dengan siswa yang mengikuti pembelajaran konvensional pada siswa kelas IV SD di Gugus VIII Kecamatan Seririt. Kompetensi IPA siswa setelah dibelajarkan dengan model pembelajaran kooperatif tipe TPS berbasis lingkungan lebih baik daripada siswa yang dibelajarkan dengan pembelajaraan konvensional. Dalam pembelajaran guru salah satu faktor penting yang dapat mempengaruhi kompetensi IPA siswa. Karena guru yang memilih model yang akan diterapkan dalam proses pembelajaran di kelas maupun di luar kelas. Pemilihan model yang tepat akan memberikan manfaat bagi proses pembelajaran. Dalam proses pembelajaran, pasti ada siswa yang mengalami kesulitan sehingga menimbulkan pertanyaan dari siswa tersebut. Oleh karena itu, guru harus bisa memilih model yang tepat dan inovatif untuk meningkatkan sikap dan kompetensi pengetahuan siswa. Menurut Alfahmi (2014), model pembelajaran kooperatif tipe TPS dapat memotivasi siswa untuk selalu mempersiapkan diri bersama dengan kelompoknya dalam memahami setiap materi pembelajaran. Selain itu, menurut Kurniasih dan berlin (2016), model pembelajaran TPS adalah salah satu model pembelajaraan yang memberikan siswa kesempatan untuk berpikir cepat dan bekerjasaama dengan siswa lain dalam memecahkan masalah sehingga mampu mempengaruhi pola interaksi siswa saat proses pembelajaraan berlangsung.

Temuan ini sejalan dengan penelitian Handayani (2017) yang mengungkapkan bahwa terdapat perbedaan yang signifikan kompetensi IPA kelompok siswa yang dibelajarkan melalui model 
pembelajaraan TPS berbantuan media question card dengan kelompok siswa yang dibelajarkan dengan pembelajaran konvensional. Selain itu, temuan ini didukung oleh penelitian Suryaningsih (2017) yang memperoleh hasil bahwa terdapat perbedaan penguasaan kompetensi IPA siswa yang dibelajarkan melalui model pembelajaran TPS dengan kelompok siswa yang dibelajarkan dengan pembelajaran konvensional.

Berdasarkan penelitian yang telah dilakukan dan diperkuat oleh beberapa teori dan temuan di atas, memperkuat bahwa model pembelaraan kooperatif tipe TPS berbasis lingkungan berpengaruh terhadap kompetensi IPA siswa.

Peningkatan yang diperoleh dalam penelitian ini yaitu sikap peduli lingkungan siswa dan kompetensi IPA. Peningkatan sikap peduli lingkungan dan kompetensi IPA berbeda-beda, tinggi atau rendahnya peningkatan ini tergantung pada motivasi, dorongan serta karakter dari berbagai model-model pembelajaran yang bervariasi di dunia pendidikan. Sehingga hal ini secara tidak langsung menyatakan bahwa memerlukan analisis yang cukup matang dalam membuat keputusan dalam hal penetapan model pembelajaran mana yang layak digunakan dan memang akan memberikan hasil yang positif sesuai dengan tujuan pendidikan yang dimiliki oleh sekolah.

Hasil penelitian ini memberikan justifikasi kepada guru agar dapat menerapkan model pembelajaran kooperatif tipe Think Pair Share (TPS) berbasis lingkungan dalam pembelajaran IPA sehingga pembelajaran menjadi berpusat pada siswa (student center) yang nantinya berpengaruh terhadap sikap peduli lingkungan dan kompetensi pengetahuan IPA siswa. Selain itu, penelitian ini juga mendorong para guru yang ada di dalam sistem pendidikan untuk lebih mengeksplorasi dan memahami lebih detail mengenai model-model pembelajaran yang sebaiknya digunakan dalam proses pembelajaran.

\section{Simpulan Dan Saran}

Berdasarkan hasil pengujian hipotesis dan pembahasan, maka simpulan dari penelitian ini adalah sebagai berikut: (1) terdapat perbedaan secara simultan sikap peduli lingkungan dan kompetensi IPA siswa kelas IV SD Gugus VIII Kecamatan Seririt. Hal ini dibuktikan dari hasil analisis Pillai's Trace, Wilks' Lambda, Hotelling Trace, Roy's Largest Root memiliki signifikansi sebesar 0,000 < 0,05. Hal ini berarti, terdapat pengaruh yang simultan model pembelajaran kooperatif tipe TPS berbasis lingkungan terhadap sikap peduli lingkungan dan kompetensi IPA siswa kelas IV SD Gugus VIII Kecamatan Seririt. (2) terdapat perbedaan sikap peduli lingkungan siswa kelas IV SD Gugus VIII Kecamatan Seririt. Sikap peduli lingkungan pada siswa yang mengikuti model pembelajaran kooperatif tipe TPS berbasis lingkungan lebih baik dibandingkan siswa yang mengikuti pembelajaran konvensional. Hal ini dibuktikan dari hasil analisis Between-Subjects Effects menunjukkan nilai sig sebesar 0,000 <0,05. Di samping itu, analisis Pairwise Comparisons dengan nilai Mean Difference (I-J) sebesar 11.967 (bernilai positif) dengan signifikansi sebesar $0,000<0,05$. Hal ini berarti, terdapat pengaruh yang signifikan model pembelajaran kooperatif tipe TPS berbasis lingkungan terhadap sikap peduli lingkungan siswa kelas IV SD Gugus VIII Kecamatan Seririt. (3) terdapat perbedaan kompetensi IPA siswa kelas IV SD Gugus VIII Kecamatan Seririt. Kompetensi IPA pada siswa yang mengikuti model pembelajaran kooperatif tipe TPS berbasis lingkungan lebih baik dibandingkan siswa yang mengikuti pembelajaran konvensional. Hal ini dibuktikan dari hasil analisis Between-Subjects Effects menunjukkan nilai sig sebesar 0,013<0,05. Di samping itu, analisis Pairwise Comparisons dengan nilai Mean Difference (I-J) sebesar 6.367 (bernilai positif) dengan signifikansi sebesar $0,000<0,05$. Hal ini berarti, terdapat pengaruh yang signifikan model pembelajaran kooperatif tipe TPS berbasis lingkungan terhadap kompetensi IPA siswa kelas IV SD Gugus VIII Kecamatan Seririt.

Berdasarkan temuan penelitian, disarankan (1) Kepada guru agar menerapkan model pembelajaran kooperatif tipe TPS Berbasis Lingkungan, karena hasil penelitian membuktikan bahwa penggunaan model pembelajaran kooperatif tipe TPS mampu meningkatkan sikap peduli lingkungan dan kompetensi pengetahuan IPA siswa. (2) Kepada sekolah agar dapat menggunakan hasil penelitian ini sebagai bahan acuan pedoman untuk membimbing guru-guru dalam melaksanakan pembelajaran dengan menggunakan model pembelajaran, untuk meningkatkan sikap peduli lingkungan dan kompetensi pengetahuan IPA siswa. 


\section{Daftar Rujukan}

Agung, A. A. G. 2017. Buku Ajar Metodologi Penelitian Pendidikan. Malang: Aditya Media Publishing.

Alfahmi, A. M. 2014. "Penerapan Model Pembelajaran Kooperatif Tipe TPS untuk Meningkatkan Hasil Belajar Siswa Pada Mata Pelajaran IPS di Sekolah Dasar." E-journal PGSD, Volume 02 Nomor 02, (hlm. 1-11). Tersedia pada http://media.neliti.com/media/publications/251751-none912733e1.pdf (diakses tanggal 3 januari 2019).

Astawan, I G dan Rati N W. 2016. "Pengaruh Model Pembelajaran Kuantum Dan Teknik Merangkum Terhadap Penalaran Mahasiswa." E-journal PGSD Undiksha, Volume 3 (hlm 1-9). Tersedia pada https://media.neliti.com/media/publications/85726-none-ce3fd1f6.pdf (diakses tanggal 06 juni 2019).

Bundu, P. 2006. Penilaian Keterampilan Proses dan Sikap Ilmiah dalam Pembelajaran Sains Sekolah Dasar. Jakarta: Depdiknas Dirjen Pendidikan Tinggi Direktorat Ketenagaan.

Candiasa, I M. 2010b. Pengujian Instrumen Penelitian Disertai Aplikasi ITEMAN dan BIGSTEPS. Singaraja: Undiksha Press.

Deruyter, S. B. 2013. “Pengaruh Model Pembelajaran Kooperatif tipe TPS Berbasis Lingkungan Terhadap Hasil Belajar IPA Siswa Kelas V SD Gugus I Kecamatan Buleleng”. E-journal PGSD Undiksha. Vol 1. Tersedia pada http://journal.undiksha.ac.id/index.php/JJPGSD/ article/viewFile/841/714 (diakses tanggal 3 januari 2014).

Febrianti, R. 2017. "Implementasi Kedisiplinan Dalam Membentuk Sikap Peduli Lingkungan Pada Siswa Kelas IV SD Negeri 111/1 Mutiara Bulian." Artikel Ilmiah, (hlm. 1-37). Tersedia pada http://repository.unja.ac.id/1531/1/A1D112076-ARTIKEL.pdf (diakses tanggal 3 januari 2019).

Handayani, N P. I. 2017. "Pengatuh Model Pembelajaran TPS Berbantuan Question Card Terhadap Kompetensi IPA." E-JOURNAL pgsd Undiksha, Volume 5, (hlm 1-10). Tersedia pada https://ejournal.undiksha.ac.id/index.php/JIPGSD/article/viewFile/10633/6759 (diakses tanggal 3 januari 2019).

Kurniasih, Imas dan Berlin S. 2016. Ragam Pengembangan Model Pembelajaran Untuk Peningkatan Profesionalitas Guru. Jogjakarta: Kata Pena.

Santyasa, I W. 2005a. Buku Ajar Belajar dan Pembelajaran. Singaraja: Undiksha Press.

Suherman. 2014. "Implementasi Kurikulum Baru Tahun 2013 Mata Pelajaran Pendidikan Jasmani." Mimbar PGSD, Volume $1 . \quad$ Tersedia pada http://ejournal.upi.edu/index.php/mimbar/article/viewFile/866/601 (diakses tanggal 03 januari 2019).

Sumantri, M.S. 2015. Strategi Pembelajaran: Teori dan Praktik di Tingkat Pendidikan Dasar. Jakarta: Rajawali Pers.

Suprijono, A. 2009. Cooperatif Learning dan Aplikasi Paikem. Yogyakarta: Pustaka Belajar.

Suryaningsih, N K. E. 2017. Pengaruh Model Pembelajaran Kooperatif Tipe TPS Terhadap Penguasaan Kompetensi IPA Siswa Kelas IV SD." E-journal PGSD Undiksha, Volume 5, (hlm 1-13). Tersedia pada http:// C:/Users/user/Downloads/37-10784-1-SM\%20(2).pdf (diakses tanggal 03 januari 2019). 
Suwatra, Ign. W., Sudarma, I K, dan Tegeh, I M. 2015. Belajar dan Pembelajaran Sekolah Dasar. Singaraja: Undiksha.

Wati, D. A. 2017. “Upaya Meningkatkan Sikap Peduli Lingkungan”. Artikel Ilmiah (hlm 1-14). Tersedia pada http://repository.umo.ac.id/3740/3/BAB\%20II.pdf (diakses tanggal 3 januari 2019). 